Revista de Estudios Histórico-Jurídicos

[Sección Historia de los Derechos Patrios de América]

XXXVI (Valparaíso, Chile, 2014)

[pp. 273 - 290]

\title{
El CONGRESO NACIONAL DE FRAY MELCHOR DE TAlamantes: Primer PROYeCto CONSTITUCIONAL DEL MÉXico IndePENDIENTE
}

[Friar Melchor de Talamantes' National Congress: First Constitutional

Project of an Independent Mexico]

\author{
Juan Pablo Pampillo Baliño* \\ Universidad Anáhuac, México
}

\begin{abstract}
RESUMEN
Este artículo presenta y revalora el pensamiento político y jurídico de Fray Melchor de Talamantes, precursor y principal ideólogo de la Independencia de México, quien, elaboró el primer proyecto de organización constitucional de ese país.

Palabras Clave

Fray Melchor de Talamantes - Congreso nacional de México.
\end{abstract}

AbSTRACT

This article presents and revaluates the political and legal thought of Friar Melchor de Talamantes, precursor and chief ideologist of Mexican Independence, who drafted the first constitutional organization project of said country.

\section{KEYWORDS}

Friar Melchor de Talamantes - National Congress of the Kingdom of New Spain.

ReCibido el 2 de abril y ACEPTADO 26 de julio de 2014

* Doctor en derecho por la Universidad Complutense de Madrid. Director fundador del Centro de Investigaciones de la Escuela Libre de Derecho y actualmente Coordinador del Centro Anáhuac para el Desarrollo Jurídico. Correo electrónico: juanpablopampillo@yahoo.com.mx 


\section{INTRODUCCIÓN}

Aunque la historia no es meramente un recuento de hechos, una relación de fechas, un inventario de documentos ni el conjunto de la biografía de ciertos personajes influyentes, sino más bien la narración documental comprensiva del pretérito desde el presente, tampoco puede dejar de lado la mención de ciertos hitos y antecedentes, que nos ofrecen algunas de las razones explicativas más profundas de los procesos que recorren el desenvolvimiento de los pueblos, sus instituciones, sus necesidades, sus problemas y sus mismas realizaciones culturales ${ }^{1}$.

En éste último sentido, este artículo busca presentar y revalorar el Congreso Nacional del Reino de Nueva España como el primer bosquejo de organización política propuesto para independizar a México de España.

En razón de lo anterior, es decir, de la extraordinaria importancia del documento, al tratarse del primer proyecto de organización constitucional para emancipar a una nueva nación y de uno de los primeros planes para articular una especie de "Commonwealth" iberoamericana, puede decirse que es un documento prácticamente desconocido, tanto entre los historiadores, cuanto entre los juristas y politólogos. ${ }^{2}$

Por la misma razón, el presente artículo busca reivindicar a la persona del autor del anterior proyecto: el mercedario peruano fray Melchor de Talamantes, quien -a pesar del olvido en que se encuentra relegado- en realidad fue el primer y más ilustrado ideólogo de la Independencia de México.

\section{El hombre y su Circunstancia: Talamantes, Nueva España, 1808}

Fray Melchor de Talamantes Salvador y Baeza, nació en la ciudad de Lima, Virreinato del Perú, el 10 de enero de $1765^{3}$.

\footnotetext{
${ }^{1}$ Sobre la historia, la historiografía, sus objetos y métodos me he extendido en PampiLlo Baliño, Juan Pablo, Historia general del derecho (México, Oxford, 2008).

${ }^{2}$ Dentro del presente artículo se recogen sintéticamente algunos de los resultados de una investigación iniciada en 2007, con motivo del Simposio Internacional 1808: a doscientos años y el origen de los derechos humanos, organizado por el Anuario Mexicano de Historia del Derecho y por el Instituto de Investigaciones Jurídicas de la Universidad Nacional Autónoma de México, y el Congreso Internacional sobre la Iglesia Católica ante la Independencia de la América Española organizado por el Ateneo Pontificio Regina Apostolorum y la Universidad Europea de Roma; investigación que concluyó con la publicación de mi libro El primer constitucionalista de México. Talamantes: ideologia y proyecto para la América Septentrional (México, Porrúa, 2010).

${ }^{3}$ Son pocas y escuetas las noticias biográficas que tenemos sobre el P. Talamantes. Además de los datos sacados de la causa que se instruyó en su contra en 1808 y de los diversos papeles personales que obran dentro de la misma, sigo y pueden consultarse con relativa facilidades las siguientes semblanzas: GonZÁlez OBREgón, Luis (compilador), Fray Melchor de Talamantes, Biografía y escritos póstumos (México, Secretaría de Relaciones Exteriores, 1909) reeditada como Fray Melchor de Talamantes, Argumentos a favor de la Independencia de México ("Presentación" y bibliografía de Luis González y textos, México, Ediciones del Centro de Documentación Política, 1979), p. 36 (por su más fácil acceso, las citas se harán con remisión a esta segunda edición); Romero del Valle, Emilia, Fray Melchor de Talamantes, en Historia Mexicana. Revista trimestral publicada por El Colegio de México, 11 (México, 1961). Véanse igualmente las semblanzas gene-
} 
Hizo sus primeros estudios con fray Manuel de Alcocer, ingresando posteriormente a la Orden de la Merced, donde una vez concluido su bachillerato, pasó a estudiar y graduarse como doctor en teología en la Universidad de San Marcos, siendo después opositor a las cátedras de Filosofía, Teología y Sagrada Escritura.

Su inteligencia y estudios lo llevaron a ocupar desde muy joven posiciones de gran importancia, habiendo sido apenas a los veintiocho años asistente del virrey Francisco de Gil y Lemus.

A pesar de no contar con mayores datos sobre la vida de Talamantes en Lima ${ }^{4}$, sabemos que conoció al doctor Hipólito Unánue, precursor de la independencia del Perú y es posible conjeturar con fundamento que tuvo acceso a diversas lecturas, que completaron su formación intelectual con las últimas ideas del liberalismo y de la ilustración ${ }^{6}$. De hecho, existe evidencia circunstancial de que Talamantes era aficionado a la lectura de autores proscritos por el Tribunal del Santo Oficio, siendo asiduo a círculos literarios ilustrados, motivos que quizás expliquen su traslado a Nueva España ${ }^{7}$.

rales: "Fray Melchor de Talamantes", en Miquel I Vergés, José María, Diccionario de Insurgentes (2a edición, México, Porrúa, 1980); y "Talamantes Salvador y Baeza Melchor" en Álvarez, José Rogelio (director), Enciclopedia de México (México, 1998), XIII. La "Causa instruida contra Fr. Melchor de Talamantes por sospechas de Infidelidad al Rey de España y de adhesión á las doctrinas de la Independencia de México" puede consultarse en GarCíA, Genaro, Documentos históricos mexicanos (edición facsimilar de la obra conmemorativa del primer centenario de la Independencia de México, publicada por la Secretaría de Instrucción Pública y Bellas Artes en 1910, México, SEP, 1985), VII. Los papeles de la causa se encuentran en el Archivo General de la Nación, caja 586, dos volúmenes. Es de especial interés para su biografía la "Memoria de los papeles pertenecientes al P. Fr. Melchor Talamantes" del 25 de abril de 1809; y en especial el relacionado como "Un cuaderno de a folio con veinte y ocho foxas, titulado: Documentos comprobantes del mérito y destinos de Fr. Melchor Talamantes y Baeza, del Orden de la Merced" y "Un cuaderno de cuarenta foxas que contiene los Testimonios de Fees de Bautismos, informaciones del mencionado Padre Talamantes, \& dentro del, una Bula de N. SSmo. Padre Pio Sexto, y un Arbol Genalógico, en quarteron de papel comun".

${ }^{4}$ Son muchos los cabos que aún permanecen pendientes de atar para reconstruir la biografía y el pensamiento de Talamantes. De manera especial, habría que investigar más sobre su educación y actividades en Perú, en lo particular, sobre la figura de Manuel de Alcocer, sobre sus maestros y relaciones en la Universidad de San Marcos, así como el alcance de sus vínculos con Hipólito Unánue y con sus hermanos de la Merced. Igualmente sería deseable conocer los libros disponibles en su convento, esclarecer mejor la naturaleza de su relación con Ramón de Rozas, en su caso con el barón de Nordenflicht, así como explorar otros posibles vínculos, por ejemplo con el abate jesuita peruano Juan Pablo Viscardo y Guzmán (1748-1798), exiliado después de la expulsión de la Compañía en 1767 en Módena, pero pendiente de la situación americana, quien escribió en 1791 en Londres el texto en francés Lettre aux Espagnols américains, pronunciándose a favor de la emancipación de la América Española.

${ }^{5}$ Hipólito Unánue y Pavón (1755-1833), médico y profesor de medicina de la Universidad de San Marcos de Lima, precursor de la independencia de Perú. Fue de los firmantes del Acta de Independencia de Perú, siendo su primer ministro de hacienda bajo el general José de San Martín y posteriormente de Simón Bolívar.

${ }^{6}$ Romero del Valle, Fray Melchor, cit. (n. 4), p. 29.

${ }^{7}$ En efecto, la causa iniciada por la en contra del doctor Ramón de Rozas, precisamente en 1799, es un incidente que pudiera explicar el viaje de fray Melchor a nuestra patria; especialmente si consideramos que dentro de dicha causa, se rindió testimonio sobre ciertas lecturas 
En cualquier caso, Talamantes desembarcó en Acapulco en noviembre de 1799, pasando después a hospedarse en el convento principal de la Merced en la Ciudad de México.

De su estancia en la capital de Nueva España, sabemos que debió serle bastante cómoda, pues no guardaba sino relativamente la clausura, dedicando largas horas al estudio y asistiendo a diferentes tertulias ${ }^{8}$. Además, poco tiempo después de haberse establecido, empezó a participar en diversos actos públicos de relieve, relacionándose con algunos de los personajes más prominentes de la Ciudad de los Palacios?.

De hecho, la consideración social e intelectual que alcanzó, le valió que el virrey José de Iturrigaray lo nombrase en enero de 1807 como "principal comisionado" para reunir y ordenar diversos documentos relativos a las Provincias Internas, con el propósito de fijar los límites entre Texas y la Luisiana.

La titánica empresa que desarrolló a título honorífico, le permitió consultar diversas bibliotecas públicas y visitar varias particulares; pudo tomar abundantes notas de diversos archivos e incluso obtuvo de diferentes dependencias, manuscritos e informes; llegando incluso a solicitar del Tribunal del Santo Oficio algunos libros censurados, como los mapas de las obras de François de Raynal y del doctor Robertson ${ }^{10}$.

Sin embargo, en 1808, el desasosiego que trajo consigo la noticia de la abdicación de los reyes de España y de la invasión napoleónica a la metrópoli, capturó de inmediato la atención de fray Melchor.

Desde el 14 de julio -cuando llegaron las primeras noticias- hasta el 16 de septiembre -en que fue depuesto el virrey Iturrigaray y aprehendido Talamantes-, nuestro personaje abandonó su comisión para la cuestión de límites, dedicándose a la reflexión y discusión de los anteriores acontecimientos ${ }^{11}$.

comprometedoras. Cfr. Medina, José Toribio, Historia del Tribunal del Santo Oficio de la Inquisición en Chile (Santiago de Chile, Fondo Histórico y Bibliográfico, 1952), pp. 655-656.

${ }^{8}$ Incluso hacia 1807 se le permitió instalar un estudio en una casa próxima al convento. Cfr. "Causa instruida", en GarCía, G., Documentos histórico, cit. (n. 4).

${ }^{9}$ Nos es conocida, por ejemplo, su cercanía con el capellán del palacio virreinal, el prestigio de que gozaba entre los síndicos del Ayuntamiento de la Ciudad México, sus relaciones con Jacobo de Villaurrutia, oidor de la Sala del Crimen de la Real Audiencia y director del Diario de México -quien le nombró censor del mismo-, así como su participación asidua en las tertulias literarias de los marqueses de Guardiola y de Uluapa, en las de la intendenta de San Luis Potosí y en las del también marqués de San Juan de Rayas. Sobre estas buenas relaciones de Talamantes, confróntense a Romero Del Valle, Fray Melchor, cit. (n. 4), pp. 29 ss.

${ }^{10}$ En efecto, la Inquisición le manifestó al virrey su desconfianza respecto del P. Talamantes, en carta fechada el 18 de febrero de 1808. Ibíd., p. 15.

${ }^{11}$ Sobre la evolución de los acontecimientos de 1808 y el consecuente desarrollo e influencia del liberalismo hispánico en ambos lados del océano, véase la siguiente obra, recientemente publicada: BREÑA, Roberto, El primer liberalismo español y los procesos de emancipación de América, 1808-1824. Una revisión historiográfica del liberalismo hispánico (México, Colegio de México, 2006). También puede consultarse con provecho la obra colectiva coordinada por CHUsT, Manuel, 1808. La eclosión juntera en el mundo hispano (México, Fondo de Cultura Económica, 2007). Una visión de conjunto también puede encontrarse en BRADING, David, Orbe Indiano. De la monarquía católica a la República criolla. 1492-1867 (traducción de Juan José Utrilla, 
Durante los dos intensos meses en que fueron fluyendo las noticias sobre los hechos que se sucedían en la península -motín de Aranjuez, ocupación francesa, abdicaciones de Bayona, levantamientos y formación de las diversas juntas-, Talamantes encauzó sus preocupaciones externando sus puntos de vista -de palabra y circulando sus escritos- en las tertulias de los marqueses de Uluapa y de Guardiola, en el Portal de Mercaderes, en la relojería de Blasio y entrevistándose con el fiscal de lo Civil de la Real Audiencia, Ambrosio Sagarzurrieta, así como con algunos síndicos del Ayuntamiento, como Juan Francisco de Azcárate y Francisco Primo de Verdad y Ramos ${ }^{12}$.

En aquéllos difíciles meses, la opinión fue unánime en su condena a la invasión napoleónica, desconociendo la usurpación de la monarquía. Se dividió sin embargo en dos grupos respecto a la actitud que debía asumir el virreinato.

Por un lado, la facción representativa de los intereses peninsulares -arraigada en el seno de la Real Audiencia- consideraba que el gobierno de la Nueva España debía proseguir sin ninguna alteración, reconociendo la autoridad de las juntas peninsulares. Por el otro lado, el partido criollo -atrincherado dentro del Ayuntamiento de la Ciudad de México- pensaba que ante la vacatio regis era necesario formar una junta similar a las que se organizaron en la metrópoli, que reasumiera la soberanía durante la ausencia del monarca y que confirmase a su vez a las autoridades del reino. Mientras tanto el virrey Iturrigaray, si bien simpatizaba con el partido criollo, asumió una actitud más bien tímida y ambigua, que posibilitó el que la facción peninsular se adelantara en deponerlo, sustituirlo por Pedro Garibay y aprender a los principales simpatizantes del grupo americanista, incluidos el propio virrey, los síndicos Azcárate y Primo de Verdad y desde luego Melchor de Talamantes ${ }^{13}$.

México, Fondo de Cultura Económica, 1991). Sobre el caso mexicano, pueden verse los enfoques tradicionales de Torre Villar, Ernesto de la, La independencia de México (México, Fondo de Cultura Económica, 1992); Miranda, José, Vida colonial y albores de la Independencia (México, Secretaría de Educación Pública, 1972); y de VilLoro, Luis. El proceso ideológico de la Revolución de Independencia (México, Universidad Nacional Autónoma de México, 1983). Véase también a Ávila, Alfredo - Guedea, Virginia (coordinadores), La Independencia de México: temas e interpretaciones recientes (México, Universidad Nacional Autónoma de México, 2007). Dentro del número 61 de la revista Metapolitica. La mirada limpia de la politica, véanse los ensayos de Ávila, Chust, Meyer y Villegas, entre otros, reunidos en torno al dossier 1808: Napoleón y la Independencia (septiembre-octubre de 2008), XII.

${ }^{12}$ En ese sentido las declaraciones de los anteriores personajes y del escribiente del P. Talamantes Juan Nepomuceno Trujillo, quien testificó en la causa que fray Melchor concurría a dichas tertulias y reuniones, habiéndole pedido hacer copias de los opúsculos Congreso Nacional y Representación Nacional, que le había dicho que quería entregar, entre otras personas, al virrey, a Azcárate, a Trujillo y a Villaurrutia. Cfr. "Causa instruida" en GARCíA, G., Documentos histórico, cit. (n. 4).

${ }^{13}$ Talamantes fue aprehendido a las 6 de la mañana, reteniéndosele primeramente en el Colegio de San Fernando, del que se intentó fugar, y siendo trasladado la misma noche del 16, por motivos de seguridad, a las cárceles del Arzobispado, de donde poco después fue conducido a la prisión del Santo Oficio. La causa que se formó contra Talamantes -cuya referencia de consulta fue consignada anteriormente- fue instruida en razón de su condición religiosa por dos jueces: el oidor decano Ciriaco González Carvajal y el provisor y vicario general Pedro Fonte, como representantes de las jurisdicciones real y eclesiástica respectivamente. Talamantes fue 
Dentro de las discusiones que se produjeron en Nueva España -sesiones de cabildo, de Real Acuerdo, y Junta General- Talamantes intervino activamente, intercambiando perspectivas con varios de los protagonistas, así como circulando también algunos escritos suyos, entre los que destacan fundamentalmente dos: el Congreso Nacional del Reino de la Nueva España, fechado el 23 de julio, aunque remitido al Ayuntamiento hasta el 23 de agosto y firmado bajo el seudónimo de Toribio Marcelino Fardanay; y la Representación nacional de las colonias. Discurso filosófico, remitida el 25 de agosto y firmada bajo el seudónimo de Yrsa, verdadero patriota $^{14}$.

\section{SOBERANÍA, NACIÓN, INDEPENDENCIA Y ORGANIZACIÓN DENTro del Congreso Nacional.}

El pensamiento del P. Talamantes presenta, como el de sus contemporáneos, tres grandes influencias ${ }^{15}$ : i) la Ilustración ${ }^{16}$; ii) el iusnaturalismo moderno racionalista ${ }^{17}$; y iii) el pensamiento tradicional castellano, sobre todo el de la segunda

interrogado en varias ocasiones; le fueron recogidos e inventariados sus libros, papeles, muebles y enseres - tanto de su celda conventual cuanto del apartamento contiguo que rentaba- y rindieron testimonio dentro de su procedimiento varios de sus hermanos religiosos, así como diversas personalidades, como el propio síndico Azcárate. Dentro del juicio, se le acusó y condenó por haber difundido, personalmente y por escrito, ideas y argumentos contrarios a la fidelidad que las colonias debían a su metrópoli y a su rey y que conducían por lo mismo a la independencia del virreinato. Para abril de 1809 fray Melchor fue sacado de las cárceles de la Inquisición, de donde se le condujo a Veracruz a la fortaleza San Juan de Ulúa, donde la peste de la fiebre amarilla se había esparcido, hecho que -según González Obregón- era del conocimiento del virrey. A los pocos días, Talamantes se contagió de dicha peste, complicándosele con vómito prieto. Murió el 9 de mayo, siendo enterrado en el cementerio de la Puntilla.

${ }^{14}$ La versión original de ambos documentos se encuentra en el Archivo General de la Nación; García Izcazbalceta la recoge en su redacción original en el tomo VII de sus Documentos Históricos que hemos venido citando (n. 4), donde se encuentran también los demás escritos del P. Talamantes Una versión con la ortografía actualizada se encuentra en GONZÁLEz OBREgón, Fray Melchor, cit. (n. 4).

${ }^{15}$ En este mismo sentido se han pronunciado la mayor parte de los estudiosos del tema. Por ejemplo, Villoro, Luis, Elproceso, cit. (n. 12), p. 205, ha expuesto: "Tres parecen ser las corrientes principales de que nutre, por ahora su pensamiento. La más importante, es el jusnaturalismo racionalista (Grocio, Puffendorf, Heinecio), que se ligaba, sin demasiadas dificultades, a la doctrina de los jesuitas ilustrados; éstos siguiendo a Suárez y tal vez a Juan de Mariana, enseñaron que la soberanía radicaba inmediatamente en el pueblo y que éste transmitía sus derechos al monarca, mediante un pacto. La unión de estas dos corrientes se hace clara en Francisco Xavier Alegre. En sus Institutionum Teologicaroum, de 1789 [...]. Sobre este fondo de pensamiento se sumaban otras influencias. Los autores ilustrados españoles, sobre todo Jovellanos y Martínez Marina [...]. Por último, las ideas francesas: Rousseau, Montesquieu, Voltarie, la Enciclopedia [...]”.

${ }^{16}$ Sobre el pensamiento de la ilustración puede verse la obra clásica de CASSIRER, Ernst, La filosofía de la ilustración (traducción de Eugenio Imaz, México, Fondo de Cultura Económica, 1981). De especial interés es el capítulo 6: "Derecho, Estado y Sociedad". Igualmente puede consultarse con provecho a IM HoF, Ulrico, La Europa de la ilustración (traducción de Bettina Blanc, Barcelona, Crítica, 1993).

${ }^{17}$ En general sobre el iusnaturalismo moderno racionalista, pueden verse las exposiciones panorámicas de Fassò, Guido, Historia de la filosofía del derecho (traducción de José. F. Lorca, 
escolástica y en especial el de F. Suárez ${ }^{18}$; así como los principios jurídicos contenidos en las Recopilación de las leyes de Indias ${ }^{19}$.

Por lo que hace a la influencia de la Ilustración, ésta se dejó sentir sobre todo durante la segunda mitad del siglo XVIII, como resultado del despotismo ilustrado y las reformas borbónicas ${ }^{20}$. Sobresale la difusión de ciertos libros, que aunque prohibidos por la Inquisición ${ }^{21}$, en realidad circularon en Nueva España, algunos

Madrid, Pirámide, 1966), II; Pampillo Baliño, Juan Pablo, Historia general del derecho (México, Oxford, 2008); y de Rodríguez Paniagua, José María, Historia del pensamiento jurídico (Madrid, Universidad Complutense, 1996), I. Específicamente sobre el pensamiento de Grocio y de Puffendorf, puede consultarse la obra de VILLEY, Michel, Los fundadores de la escuela moderna del derecho natural (Buenos Aires, 1978). Para el pensamiento de Wolff puede verse la monografía de Pérez Cayana, María Luisa, Christian Wolff(Madrid, Ediciones del Orto, 1995).

${ }^{18}$ Sobre el pensamiento de Suárez vale la pena consultar la completísima obra de RommEN, Heinrich, La teoría del estado y de la comunidad internacional en Francisco Suárez (traducción por Valentín García Yebra, Buenos Aires - Madrid, Instituto de Derecho Internacional de Buenos Aires - Instituto Francisco de Vitoria de Madrid, 1951). Puede verse también la obra general, aunque menos amplia de Gallegos Rocafull, José María, La doctrina política del P. Francisco Suárez (México, Jus, 1948). Sobre el origen del poder y la teoría pactista de la mediación véase: GÓmez Robledo, Ignacio, El origen del poder político según Francisco Suárez (México, Jus, 1948). En general sobre la segunda escolástica española puede verse la obra de CARRIO, Venancio O.P., La teología y los teólogos-juristas españoles ante la conquista de América (Madrid, Escuela de Estudios Hispanoamericanos de la Universidad de Sevilla, 1944).

${ }^{19}$ En general sobre el derecho indiano, pueden consultarse las obras clásicas de DougnaC, Antonio. Manual de historia del derecho indiano (2a edición. México, Mc Graw Hill, 1998); Muro Orejón, Antonio, Lecciones de historia del derecho hispano-indiano (México, Porrúa - Escuela Libre de Derecho, 1989); Ots CaPdequí, J. M., El Estado español en Indias (México, Fondo de Cultura Económica, 1993); TAU AnzoÁtegui, Víctor, ¿Qué fue el derecho indiano? (Buenos Aires, Abeledo Perrot, 1982). Recientemente ha publicado también un extraordinario libro el maestro De Icaza Dufour, Francisco, "Plus Ultra". La Monarquía Católica en Indias, 1492-1898 (México, Porrúa - Escuela Libre de Derecho, 2008). Igualmente vale la pena consultar el libro de GonZÁlez, María del Refugio, El Derecho indiano y el derecho provincial novohispano. Marco historiográfico y conceptual (México, Universidad Nacional Autónoma de México, 1995), Sobre el derecho castellano, pueden consultarse los clásicos manuales de GarCía-Gallo, Alfonso, Manual de historia del derecho español (6a edición, Madrid, Artes Gráficas, 1975); y TOMÁs y VALIENTE, Francisco, Manual de historia del derecho español (4a edición, Madrid, Tecnos, 1997). En general también para ambos temas pueden consultarse entre otros los textos de Cruz BarneY, Óscar, Historia del derecho en México (2a edición, México, Oxford University Press, 2007); Torre Rangel, Jesús Antonio de la, Lecciones de historia del derecho mexicano (México, Porrúa, 2005); Esquivel Obregón, Toribio, Apuntes para la historia del derecho en México ( $3^{a}$ edición, México, Porrúa, 2004); y Soberanes Fernández, José Luis, Historia del derecho mexicano (10ª edición, México, Porrúa, 2003). Sobre la organización jurídica de los virreinatos, puede verse también la obra de BARRIos, Feliciano (coordinador), El gobierno de un mundo. Virreinatos y Audiencias en la América Hispánica (Cuenca, Ediciones de la Universidad Castilla-La Mancha, 2004).

${ }^{20}$ En general sobre la ilustración española puede consultarse a DOMíngUEZ OrTiZ, Antonio. Carlos III y la España de la Ilustración (Madrid, Altaza, 1996). Cfr. también Miranda, Vida colonial, cit. (n. 12), pp. 202 ss.; y BRENA, El primer liberalismo, cit. (n. 12), pp. 259 ss.

${ }^{21}$ La Inquisición podía prohibir absoluta e íntegramente los libros o sus autores -in totum-o nada más sujetarlos a expurgación es decir, a un examen particular, que suponía a su vez la purga o modificación de los pasajes condenados. Los textos prohibidos figuraban en el Index librorum prohibitorum et expurgatorium, del cual hubo varias ediciones. Entre los géneros prohibidos se encontraban principalmente, las obras ateístas (como las de Raynal), las materialistas (como 
de ellos incluso como parte de una estrategia promovida por los Estados Unidos ${ }^{22}$.

Sin embargo, la mayor influencia sobre Talamantes la encontramos en $E l$ espiritu de las leyes de Montesquieu ${ }^{23}$ y sobre todo en El contrato social de Rous$\operatorname{seau}^{24}$. En efecto las ideas rousseaunianas en torno a la "soberanía popular" y a la "voluntad general", tuvieron una clara proyección dentro de sus escritos, si bien, en el fondo, partían de una concepción tradicional sobre el origen del poder: la del pactismo de la segunda escolástica ${ }^{25}$.

Por lo que respecta al iusnaturalismo moderno racionalista, ésta corriente de pensamiento se ocupó también del tema de la soberanía, en especial de la llamada

las de Voltaire y Rousseau), las naturalistas (como la Riqueza de las Naciones), las tolerantistas (como nuevamente la de Smith), las libertinas (como las de Raynal), las sedicioso políticas (entre las que figuran la de Rousseau) y otras sin clasificar como las de Montesquieu. Pérez-Marchand ha observado que si bien la Inquisición Española, durante la época se encargaba de "redoblar las precauciones... para impedir que pasasen a las Indias libros que pudieran llevar a los colonos el contagio de las ideas contrarias a la religión, a la dependencia y sumisión que se debían al soberano", también es cierto que durante el siglo XVIII "ocurrieron irregularidades", concluyendo: "Por lo tanto, la introducción de obras prohibidas era un suceso diario fomentado por aquellos a quienes habían inquietado ya las nuevas ideas": Pérez-MarChand, Monelisa Lina, Dos etapas ideológicas del siglo XVIII en México a través de los papeles de la Inquisición (México, Colegio de México, 1945), pp. 323, 39, 43, 92, 95. También puede consultarse con provecho a Medina, José Toribio, Historia del Tribunal del Santo Oficio de la Inquisición en México (2a edición ampliada por Julio Jiménez Rueda, México, Ediciones Fuente Cultural, 1952).

${ }^{22}$ Sobre la circulación de las obras prohibidas, en Nueva España se sabe que fue favorecida especialmente desde el norte después de la cesión de la Luisiana por su gobernador, como parte de una estrategia de propaganda revolucionaria. Cfr. Miranda, José, El influjo político de Rousseau en la Independencia mexicana, en Presencia de Rousseau. A los 250 años de su nacimiento y a los dos siglos de la aparición del Emilio y El contrato social (México, Universidad Nacional Autónoma de México, 1962). Véase también a STOETZER, Carlos. El pensamiento político en la América Española durante el periodo de la emancipación (1789-1825). Las bases hispánicas y las corrientes europeas (Madrid, Instituto de Estudios Políticos, 1966), especialmente su tomo II a partir de la página 14 .

${ }^{23}$ Sobre el pensamiento de Montesquieu, destacando también su influjo en la ilustración española, véase la excelente y completa monografía de VALlet de GoYTisolo, Juan, Montesquieu: Leyes, gobiernos y poderes (Madrid, Civitas, 1986). Véase especialmente el epígrafe: "La soberanía y la división de poderes" pp. 384 ss.

${ }^{24}$ En general sobre el pensamiento de J. J. Rousseau, véase a RuBio, José. ¿Democracia o representación? Poder y legitimidad en Rousseau (Madrid, Centro de Estudios Constitucionales, 1990); y Villaverde, María José, Rousseau y el pensamiento de las luces (Madrid, Tecnos, 1987).

${ }^{25}$ Cfr. por todos Stoetzer. El pensamiento, cit. (n. 23). En sus palabras (II, p. 14): "El influjo de Rousseau en la América española fue ayudado considerablemente por el hecho de que los intelectuales en España sostenían ideas parecidas a aquellas que estaban de moda en la Europa occidental.”. Sobre las diferencias entre el contractualismo ilustrado, especialmente el de Rousseau y el pactismo o doctrina populista de la segunda escolástica y específicamente su exposición por Francisco Suárez, puede consultarse esquemáticamente a STOETZER, Carlos, Las raíces escolásticas de la emancipación de la América Española (Madrid, Centro de Estudios Constitucionales, 1982), pp. 48 ss. También puede verse a BREÑA, El primer liberalismo, cit. (n. 12), pp. 190 ss. 
doctrina de su reversión al pueblo ${ }^{26}$. De hecho, la misma teoría contractualista de Rousseau parte de la doctrina iusnaturalista de la reversión ${ }^{27}$.

En cualquier caso, lo cierto es que la doctrina de la reversión de la soberanía propiamente procedía del pactismo de la segunda escolástica española ${ }^{28}$. De hecho, la doctrina pactista constituye el principal nutriente del discurso del P. Melchor de Talamantes.

Ahora bien, las anteriores influencias -que fueron también el contexto general y telón de fondo filosófico del discurso independentista en general- eclosionaron de un modo particular en Talamantes. Por ello, Ernesto de la Torre Villar observó, que dentro de su generación, nuestro personaje fue el "menos cauteloso", quien expuso su pensamiento "con mayor libertad”, convirtiéndose así en una "voz precursora" de la independencia ${ }^{29}$. En ese mismo sentido, para Luis Villoro, fray Melchor fue el "más osado". De hecho, fue de los pocos pensadores, que según José Miranda, se expresaron explícitamente en un "lenguaje francés ilustrado" con "resabios rousseaunianos" ${ }^{30}$. En todo caso, como ha destacado con razón Roberto Breña, el ilustre mercedario fue el único "que se declaró a favor de la independencia" ${ }^{31}$.

Afortunadamente, la determinación específica de las influencias del pensamiento del P. Melchor de Talamantes puede hacerse con relativa certidumbre, mediante la valoración de sus principales intereses y lecturas, así como tomando en cuenta el contenido de su propia biblioteca.

Por medio de la causa instruida en su contra, sabemos de acuerdo a la propia declaración de fray Melchor que sus lecturas e intereses habían sido "sovre materias Theologicas, de Religiosos, Historias, politicas, Phisicas, Medicas y de varia literatura", mientras que sus intereses han versado "principalmente sovre puntos morales y de predicación... y sovre varios otros puntos sovre que le ha sido preciso escribir según las ocurrencias' ${ }^{\prime 32}$.

Igualmente, gracias a los documentos recogidos por José Toribio Medina, sabemos que Talamantes había leído antes de 1799 El contrato social de Rousseau,

\footnotetext{
${ }^{26}$ Sobre el pensamiento iusnaturalista moderno en torno a la reversión de la soberanía, con en especial en S. Puffendorf, cfr. Stoetzer. El pensamiento, cit. (n. 23), I, pp. 194 ss.

${ }^{27}$ Más allá de las diferencias entre sus respectivas teorías sobre la soberanía, el influjo, por ejemplo, de J.J. Burlamaqui sobre Rousseau es conocido, habiendo sido destacado originalmente por Domenico Rodari. Como observa con razón Chiaramonte, José Carlos, Fundamentos iusnaturalistas de los movimientos de Independencia, en Terán, María - SERrano Ortega, José Antonio (editores), Las Guerras de Independencia en la América Española (México, Colegio de Michoacán - Universidad Michoacana de San Nicolás de Hidalgo - INAH, 2002), p. 108: “Aún la influencia misma de los grandes autores, Rousseau por ejemplo, es conveniente reubicarla sobre el trasfondo iusnaturalista de su obra [...]"

${ }^{28}$ Cfr., por todos: STOETzer. Las raíces escolásticas, cit. (n. 27).

${ }^{29}$ Torre Villar, Ernesto de la, La Constitución de Apatzingán y los creadores del Estado mexicano (México, Universidad Nacional Autónoma de México, 1978), p. 31.

${ }^{30}$ Villor, El proceso, cit. (n. 12), p. 53; Miranda, El influjo, cit. (n. 23), p. 266.

${ }^{31}$ BREÑA, El primer liberalismo, cit. (n. 12), p. 342.

${ }^{32}$ García, Genaro, Documentos históricos, cit. (n. 4), VII viene la causa completa, y en su declaración preparatoria en el punto $4^{\circ}$ p. 24 . Archivo General de la Nación, Historia, caja 586, volúmenes 1 y 2 , fojas 8-26.
} 
los Establecimientos americanos del abad Guillermo Tomás Raynal y un libro bastante olvidado en nuestros días, que levantó sin embargo una gran conmoción en su tiempo: la Historia del año dos mil cuatrocientos cuarenta, atribuido a Mercier ${ }^{33}$.

Por lo que hace a la biblioteca y papeles personales del P. Talamantes, dentro del expediente que contiene su juicio se levantaron diversas diligencias ${ }^{34}$, de las que se desprende, en primer lugar, la variedad de conocimientos intelectuales y científicos del P. Talamantes, con cierto predominio -además de los textos religiosos- de la literatura, la lingüística, la retórica, la teología moral, la historia, la política, la geografía, la botánica y el derecho, así como el conocimiento del griego, del latín, del inglés y del francés, cuya lectura haría posiblemente auxiliado por los diccionarios y gramáticas que obraban entre sus volúmenes ${ }^{35}$.

${ }^{33}$ José Toribio Medina nos revela -como se adelantó- unos datos preciosos y muy poco conocidos entre nosotros sobre las lecturas del P. Talamantes; se refiere específicamente al barón Timoteo Nordenflicht, alemán de origen, que había sido contratado por la corona para pasar a Perú a establecer diversos adelantos científicos en materia de beneficio de metales. Antes de trasladarse, el barón obtuvo permiso para leer libros prohibidos, pero fue denunciado por Vicente Gil de Taboada de haberle prestado diversas obras de Voltaire y de Montesquieu al doctor Ramón de Rozas, abusando pues del permiso concedido. Los inquisidores iniciaron una causa contra Ramón de Rozas en 1799, por lectura de libros prohibidos. Lo interesante es que dentro del expediente de Rozas, obra la declaración del padre Camilo Henríquez, quien declaró en febrero de 1803: "hablando de libros prohibidos, que el Contrato social le tuvo en su cuarto como cosa de un día y lo llevo á él el padre Talamantes de la Merced, diciéndole que le llevaba á entregar al Barón Nordenflicht por encargo de don Ramón de Rozas". Más aún, prosigue, que "el Contrato social de Ruzó [...] le entregó á Talamantes y éste á don Ramón de Rozas, quienes le leyeron, según le aseguró el padre Talamantes". Pero hay todavía más: "Que el dicho padre Talamantes le prestó la Historia del año de dos mil cuatrocientos cuarenta, justamente probibida por el Santo Oficio, porque es de las más impias que se han dado á luz; que esta obra dijo el padre Talamantes la iba á encuadernar y regalarla á don Ramón Rozas, lo que expresó en presencia de don José Pérez. Que el dicho padre Talamantes prestó también al confesante un tomo de los Establecimientos Americanos por Raynal, diciéndole que la obra pertenecía al doctor don Ramón de Rozas": MEDINA, José Toribio, Historia del Tribunal del Santo Oficio de la Inquisición en Chile, cit. (n. 9), pp. 655 y 656.

${ }^{34}$ Las principales diligencias en las que consta el inventario de libros, legajos, mapas, muebles y enseres son: a) la Certificación de los bienes que se encontraron en la casa y celda del P. Talamantes del 19 de septiembre de 1808, b) el Inventario de los papeles que los aprehensores del P. Talamantes condujeron el día de su prisión a la casa del Sr. Oidor D. Guillermo de Aguirre del 20 de septiembre, c) los Bienes exhibidos de orden de los Sres. Comisionados para que se le lleven a la prisión al P. Talamantes del propio día 20, d) el Inventario de libros y papeles de 22 de septiembre de 1808, y, por último, e) la Memoria de los papeles pertenecientes al P. Fr. Melchor Talamantes, Religioso Mercedario de la Provincia de Lima, del 25 de abril de 1809. Cfr. "Causa instruida” en García, G., Documentos histórico, cit. (n. 4). Cfr Archivo General de la Nación, caja 586, dos volúmenes.

${ }^{35}$ Entre las obras, papeles y enseres encontrados en la biblioteca de Melchor de Talamantes que fueron inventariadas dentro de la causa pueden citarse: Cuatro tomos de la Recopilación de las Leyes de Indias, un Atlas, un tomo de Gramática inglesa, un compendio de Gramática griega, la Rusticatio mexicana de Rafael Landívar, un tomo de Diurno, los Fastos de la Academia-que fueron publicados por la Real Academia de Historia-, un tomo en latín de la Dialogistica lingua Latina exercitatio de J. L. Vivis, un tomo de Gramática castellana, Breviarios, Oficios de la Merced, un tomo intitulado Entretenimientos sobre la inmortalidad del alma, Apología de la lengua vascongada, un tomo de Diccionario de la lengua inglesa, un tomo del Homo atritus, un volumen de Kempis, un tomo Teatro americano, que era una descripción de los reinos y provincias de 
De manera particular sobre los temas de soberanía, nación, colonialismo, independencia y constitución, pueden mencionarse las siguientes obras: la Recopilación de leyes de los reinos de Indias, un tomo sobre Teología moral, un tomo de Derecho público y otro de Ensayos sobre la jurisprudencia sin mención específica de sus autores, el tomo tercero de un libro de Heinecio -casi seguramente los Elementa iuris naturae et gentium-, El espiritu de las leyes de Montesquieu, La Riqueza de las naciones de Adam Smith y Alcira de Voltaire, obra dramática sobre la libertad de los americanos.

En virtud de lo anterior, tomando en cuenta sus intereses, lecturas y biblioteca, es posible afirmar que fray Melchor de Talamantes fue un pensador con una sólida formación teológica-moral, influida por la segunda escolástica española y por lo mismo arraigada en el método escolástico y en la filosofía perenne aristotélico-tomista. Pero además, nos encontramos ante un religioso familiarizado con el derecho romano, canónico, natural y especialmente con el derecho indias. Igualmente, se trata de un intelectual con amplios conocimientos de historia y actualidad política, económica y geográfica, que ha obtenido, al menos en parte, de autores ilustrados. Por último, puede asegurarse que nuestro personaje se encuentra plenamente familiarizado con el pensamiento del Iluminismo en sus diversas vertientes: i) literaria (Voltaire); ii) utópica (Mercier); y iii) político-económica (Rousseau, Montesquieu, Smith y Raynal).

Por lo que hace a sus escritos relacionados con el tema de 1808, con motivo del registro que se hizo de su celda y estudio se le recogieron los siguientes: 1) Primeras disposiciones para mantener este reino independiente de la dominación francesa (una foja sin concluir), 2) Congreso nacional del reino de Nueva España.

Nueva España, un tomo de Historia de Teodoro el Grande, el Oficio de la sangre de Cristo, un volumen de Observaciones sobre ortografía, dos tomos de la Oratoria de Quintiliano, un tomo en francés Tratado sobre la perfección del estado eclesiástico, un tomo de La riqueza de las naciones, otro volumen intitulado Ensayo sobre la jurisprudencia, un quinto tomo sobre Theología moral, un tomo de Derecho público, un folio menor en pergamino de Joh Gottlieb Heinecii tomo tercero, cuatro tomos de un Tratado de retórica de Blair, los Centones fornerianos, otro volumen de Elementos de agricultura, otro de Descripciones de plantas, otro en pergamino titulado Método para enseñar las bellas letras tomo segundo, otro de Estatutos del Colegio de Abogados, otro de Representaciones del Tribunal de Minería, tres volúmenes de distintos Sermones panegíricos, un tomo de Curso de botánica, un tomo de Tribulaciones de los fieles de Asia, Misceláneas de poesías de Castro, un tomo en francés de Montesquieu El espiritu de las leyes, Legajos de Gacetas y Diarios, una caja de instrumentos matemáticos con veinte y nueve piezas de varios tamaños, también un Mapa grande Carte generale sur le Territoriore d Orleáns, un Plan ychnographico de la ciudad de Valladolid. Dentro de una baúl cerrado con candado, se encontraron igualmente libros y papeles, que contenían diversos documentos sobre el tema de límites, incluyendo el Diario de derroteros apostólicos y militares, Documentos y la Historia del Nuevo México, Documentos de la historia eclesiástica y civil de la provincia de Texas, unas Memorias escritas para la historia de la provincia de Texas, catorce mapas, Varios legajos, carpetas y papeles sobre el tema de límites, "un legajo de varios papeles que se creen prohibidos por el Santo Oficio, manuscritos algunos y dos impresos", un libro de entradas y gastos, Varias cédulas y órdenes, varios viajes, varios mapas forrados, mapas grandes, varios escritos firmados bajo los seudónimo de Yrsa y de Toribio Marcelino Faraday, diversos decretos, documentos y representaciones. Cfr. "Causa instruida", en García, G., Documentos histórico, cit. (n. 4). Cfr. Archivo General de la Nación, caja 586, dos volúmenes. 
Expónense brevemente los graves motivos de su urgente celebración, el modo de convocarlo, individuos que deben componerlo y asunto de sus deliberaciones. (19 fojas, firmado por Yrsa, seudónimo), 3) Reflexiones sobre las ocurrencias del día (dos fojas), 4) Cartas dirigidas al señor gobernador, intendente y brigadier don Roque Abarca (cuatro fojas), 5) Representación nacional de las colonias. Discurso filosófico dedicado al excelentísimo Ayuntamiento de la M.N.M.L.I. e Imp. Ciudad de México, capital del reino. Por Yrsa, verdadero patriota (11 fojas), 6) Contestación a la Junta de Gobierno de Sevilla de 17 de junio del presente año (una foja), 7) Memorias de varios asuntos que deben serlo de obras que es necesario trabajar de intento y publicar (una foja), 8) Cuestión importante sobre el regreso de Fernando VII a la España (tres fojas sin terminar) y 9) Advertencias reservadas á los habitantes de Nueva España acerca del Congreso General (una foja sin terminar) ${ }^{36}$.

Aquí nos referiremos principalmente al Congreso nacional del reino de Nueva España, aunque remitiéndonos igualmente a los demás documentos, que indudablemente arrojan luz sobre la intención y extensión de muchos de sus planteamientos.

En primer lugar, conviene destacar cual es la interpretación que el P. Talamantes hace de la situación política de su tiempo, así como el mismo destino final de sus planteamientos. Estos dos puntos los encontramos expresados, en términos inequívocos, en sus Advertencias reservadas, en las que literalmente apunta: "aproximándose ya el tiempo de la independencia de este reino, debe procurarse que el congreso que se forme lleve en si mismo, sin que pueda percibirse de los inadvertidos, las semillas de esa independencia sólida, durable y que pueda sostenerse sin dificultad $y$ sin efusión de sangres".

La anterior interpretación de la situación prevaleciente, parte en realidad del análisis exhaustivo que presenta el $\mathrm{P}$. Talamantes dentro de su discurso filosóficopolítico sobre la Representación nacional. Dentro de dicho discurso, dedica la primera parte a exponer la naturaleza de las colonias, de las leyes coloniales y regionales y de la representación nacional, consagrándose en la segunda a desarrollar los casos en los cuales es lícito a las colonias separarse de su metrópoli.

Dentro de la primera parte de la Representación, fray Melchor advierte en primer lugar la insubsistencia del gobierno colonial por virtud de las abdicaciones, pues: "no existiendo el rey civilmente en la nación, tampoco pueden existir sus representantes. " De aquí saca fray Melchor la consecuencia de que la representación -o soberanía- es revertida al pueblo, ofreciendo una noción amplia de la misma que justificaría, dentro de su Congreso nacional del reino de Nueva España, la necesidad de convocar a una Asamblea Legislativa para la Nueva España.

En las palabras del propio Talamantes: "Se entiende por ella [por representación nacional] el derecho que goza una sociedad para que se le mire como separada, libre e independiente de cualquier otra nación. Este derecho pende de tres principios: de la naturaleza, de la fuerza y de la politica [...] [y consiste en] la facultad de organizar-

${ }^{36}$ Cfr. "Causa instruida”, en García, G., Documentos histórico, cit. (n. 4). Cfr. Archivo General de la Nación, caja 586, dos volúmenes. 
se [...] de reglar y cimentar la administración pública [...] de reponer las leyes que faltasen, enmendar las defectuosas, anular las perjudiciales y expedir otras nuevas".

En la segunda parte de la Representación, fray Melchor expone los casos en los que les es lícito a las colonias separarse de sus metrópolis, enumerando los siguientes: i) Cuando las colonias se bastan a sí mismas; ii) Cuando las colonias son iguales o más poderosas que sus metrópolis; iii) Cuando las colonias difícilmente pueden ser gobernadas por sus metrópolis; $i v$ ) Cuando el simple gobierno de la metrópoli es incompatible con el bien general de las colonias; $v$ ) Cuando las metrópolis son opresoras de sus colonias; vi) Cuando la metrópoli ha adoptado otra constitución política; vii) Cuando las primeras provincias que forman el cuerpo principal de la metrópoli se hacen entre sí independientes; viii) Cuando la metrópoli se sometiera voluntariamente a una dominación extranjera; $i x$ ) Cuando la metrópoli fuese subyugada por otra nación; $x$ ) Cuando la metrópoli ha mudado de religión; $x i$ ) Cuando amenaza en la metrópoli mutación en el sistema religioso; y xii) Cuando la separación de la metrópoli es exigida por el clamor general de los habitantes de la colonia.

Aunque, pretendidamente, Talamantes no se pronuncia por la concurrencia de las anteriores causas en el caso de la Nueva España, da a entender con absoluta claridad la presencia de la mayor parte de las mismas hacia 1808.

A partir de los anteriores antecedentes, y por lo que respecta específicamente al Congreso nacional del reino de Nueva España, partiendo de la premisa de la representación o soberanía política de la que gozan las colonias en los casos en los que les es lícito separarse de su metrópoli, Talamantes se dedica a hacer una amplia exposición de los motivos que recomiendan la convocatoria de una Asamblea Soberana dentro del contexto político de 1808.

Asimismo, expone y desarrolla la manera en la que dicha asamblea debiera integrarse y funcionar, refiriendo por último los mismos asuntos sobre los que debiera ocuparse.

Se trata, en definitiva, del primer proyecto de organización político constitucional destinado a organizar la vida independiente de México a partir de la asunción de su propia soberanía.

A lo largo del Congreso nacional, Melchor de Talamantes despliega su amplio conocimiento de las instituciones políticas y jurídicas inglesas, francesas y norteamericanas. Hace gala igualmente de sus excepcionales dotes y sentido práctico para la organización, que lo llevan a describir, de manera pormenorizada, una serie de necesidades y problemas, a cuyo examen y resolución se encontraría llamado el parlamento soberano propuesto.

El propósito de su Congreso nacional es expreso. Pretende persuadir a los lectores sobre la necesidad de: $i$ ) designar ministros plenipotenciarios para buscar apoyos económicos y militares; ii) organizar los recursos financieros del erario para emprender eventuales acciones militares defensivas y de apoyo a la metrópoli; iii) legislar en diversas materias para arreglar mejor el comercio, la industria y el gobierno, en una situación en la que no se pueden escatimar los recursos y esfuerzos para salvaguardar la integridad de la colonia y, eventualmente, contribuir a la salvación de la metrópoli. 
Ahora bien, como el nombramiento de embajadores, los acuerdos y alianzas internacionales en materia militar, económica y de empréstitos, la organización del gobierno, del comercio y de la industria y la propia preparación para la acción militar, son todos actos de soberanía, se impone -según plantea fray Melchor- la impostergable necesidad de convocar un Congreso Nacional o Asamblea Soberana, que supone en realidad una auténtica declaración de la independencia del reino colonial.

En las propias palabras de Talamantes: "careciendo de libertad la metrópoli para ejercer su soberanía y obrar expeditamente, oprimida como se halla de las tropas francesas, las grandes posesiones de las Américas, parte importante de la nación, deben entrar en posesión de los primitivos y esenciales derechos de aquélla [...]"

$\mathrm{Al}$ referirse específicamente al poder legislativo como expresión de la soberanía, Talamantes observa que "éste es un poder que existe siempre radicalmente en la nación y a los monarcas se ha confiado solamente su ejercicio".

Continuando con su exposición, fray Melchor observa que la finalidad inmediata de la instalación del Congreso es la organización del gobierno para la defensa de la nación y eventualmente de la madre patria.

Sin embargo, Talamantes no se queda con dicha finalidad inmediata, sino que prosigue hasta expresar el fin último y natural de la representación nacional, en términos que resultan muy adelantados para su tiempo.

En efecto, para Melchor de Talamantes, el Congreso deberá velar por "la salud del Estado y el beneficio de la patrio [...] el bien de todos los actuales habitantes, sin distinción de jerarquias, condiciones, naciones y sexos".

Sobre la integración del Congreso, Talamantes muestra nuevamente su amplitud de miras, pues propone que concurran al mismo, tanto los estamentos medievales, cuanto las distintas autoridades políticas y eclesiásticas, lo mismo que diputados y representantes de villas y ciudades.

Así las cosas, propone que el Congreso sea integrado, en primer lugar, por el virrey como su presidente. En segundo lugar llama a los tenientes del ejército, los presidentes de Audiencias y los intendentes de ejército, así como a los gobernadores de las provincias y los oidores y alcaldes de corte de la capital. Convoca también a su asamblea, para la representación de las Audiencias foráneas, a diputados por las mismas. Plantea la conveniencia de que acudan por igual todos los jefes de las primeras oficinas y tribunales del reino. No omite recomendar la asistencia de los títulos -es decir de los nobles- de Castilla. De la misma manera, plantea la elección de diputados, o sea, de representantes de las ciudades y villas. Por el estado eclesiástico, propone la participación del arzobispo y los obispos, de diputados de los cabildos de cada diócesis, pidiendo también la asistencia del cura más digno de cada diócesis, del inquisidor más antiguo, y de los generales y provinciales de las órdenes regulares. No desdeña tampoco a la auctoritas scientiae, extendiendo por lo mismo la participación a los rectores de universidad. Por último, declara, que en todo caso y en aras de la mayor representatividad, sería prudente considerar a todos "los demás que fuese oportuno".

Respecto del funcionamiento y asuntos sobre los que habría de versar la actividad del Congreso, describe de manera amplia y completa, desde el proto- 
colo para la celebración de los actos religiosos y el juramento de fidelidad al rey, hasta el mismo sello del reino, que según su parecer "podrá ser un águila sobre un nopal, sosteniendo del pico, inclinado al lado opuesto del nopal, el escudo de armas de la España."

Por lo que hace a las responsabilidades específicas de su Congreso, Talamantes proponía que se dedicara a organizar el gobierno, nombrando cuatro secretarios de despacho (negocios militares, civiles, eclesiásticos y de hacienda), para organizar después el ejército, confirmando por último a todos los funcionarios en ejercicio y supliendo tan solo las vacantes que existieran en los diferentes ramos y niveles.

Igualmente, para reunir los recursos económicos necesarios para la defensa del reino -y en su caso para apoyar militarmente a la metrópoli- el Congreso debería tomar las providencias necesarias para promover el comercio, ordenando la excavación de minas de azogue y el cultivo de diversas especies, así como, desde luego, fijar los impuestos correspondientes sobre dichas actividades.

Es particularmente notable la recomendación de Talamantes en el sentido de que el Congreso también debería encargarse de designar plenipotenciarios, especialmente cerca del gobierno de Estados Unidos, para que "reconozcan la independencia del reino de Nueva España”, así como para formar una alianza ofensiva, negociar un tratado de libre comercio y terminar la cuestión sobre los límites de Luisiana...

En definitiva, más allá de la incluso excesiva prolijidad de detalles con que Talamantes diseña su Congreso, nos encontramos en realidad ante un planteamiento inédito, que constituye indudablemente el primer proyecto de organización constitucional para el México Independiente.

Desafortunadamente, la forma en la que fue conjurado el activismo del partido criollo en 1808, canceló la posibilidad de una emancipación gradual, pacífica y conducida por las vías jurídicas e institucionales, que quizás hubiera asegurado un rumbo menos dramático a los acontecimientos posteriores.

También lamentablemente, la contundencia con la que fue sofocado este primer intento de búsqueda de una mayor independencia, supuso que el pensamiento y los escritos del padre Talamantes no ejercieran una mayor influencia intelectual sobre las posteriores generaciones de líderes del movimiento emancipador, que por lo demás, hubieran podido beneficiarse importante del mismo ${ }^{37}$.

Lo que puede en cambio remediarse es la relegación -y hasta el olvido- del P. Talamantes, así como el desconocimiento de su proyecto de organización constitucional.

37 “Cuando se levantaron en 1810 Hidalgo, Allende, Morelos y los demás próceres, ellos no conocieron el plan de Talamantes. Después quedó arrumbado en un archivo, sirviendo en un principio a la crítica de los enemigos de la independencia”: ROMERO, Fray Melchor, cit. (n. 4), p. 40 . 


\section{BiBLIOGRAFÍA}

García, Genaro, Documentos históricos mexicanos (edición facsimilar de la obra conmemorativa del primer centenario de la Independencia de México, publicada por la Secretaría de Instrucción Pública y Bellas Artes en 1910, México, SEP, 1985), VII.

Álvarez, José Rogelio (director), Enciclopedia de México (México, 1998), XIII, s. v. "Talamantes Salvador y Baeza Melchor".

Ávila, Alfredo - GuedeA, Virginia (coordinadores), La Independencia de México: temas e interpretaciones recientes (México, Universidad Nacional Autónoma de México, 2007).

BARrIos, Feliciano (coordinador), El gobierno de un mundo. Virreinatos y Audiencias en la América Hispánica (Cuenca, Ediciones de la Universidad Castilla-La Mancha, 2004).

BRADING, David, Orbe Indiano. De la monarquía católica a la República criolla. 14921867 (traducción de Juan José Utrilla, México, Fondo de Cultura Económica, 1991).

BRENAA, Roberto, El primer liberalismo español y los procesos de emancipación de América, 1808-1824. Una revisión historiográfica del liberalismo hispánico (México, Colegio de México, 2006).

CARrio, Venancio O.P., La teología y los teólogos-juristas españoles ante la conquista de América (Madrid, Escuela de Estudios Hispanoamericanos de la Universidad de Sevilla, 1944).

CASSIRER, Ernst, La filosofía de la ilustración (traducción de Eugenio Imaz, México, Fondo de Cultura Económica, 1981).

Chiaramonte, José Carlos, Fundamentos iusnaturalistas de los movimientos de Independencia, en Terán, María - Serrano Ortega, José Antonio (editores), Las Guerras de Independencia en la América Española (México, Colegio de Michoacán - Universidad Michoacana de San Nicolás de Hidalgo - INAH, 2002).

Chust, Manuel, 1808. La eclosión juntera en el mundo hispano (México, Fondo de Cultura Económica, 2007).

Cruz Barney, Óscar, Historia del derecho en México (2a edición, México, Oxford University Press, 2007).

Domínguez Ortiz, Antonio. Carlos III y la España de la Ilustración (Madrid, Altaza, 1996).

Dougnac, Antonio. Manual de historia del derecho indiano (2a edición. México, Mc Graw Hill, 1998).

Esquivel Obregón, Toribio, Apuntes para la historia del derecho en México (3a edición, México, Porrúa, 2004).

FAssò, Guido, Historia de la filosofía del derecho (traducción de José. F. Lorca, Madrid, Pirámide, 1966), II.

Gallegos Rocafull, José María, La doctrina política del P. Francisco Suárez (México, Jus, 1948).

García-Gallo, Alfonso, Manual de historia del derecho español (6a edición, Madrid, Artes Gráficas, 1975).

Gómez Robledo, Ignacio, El origen del poder político según Francisco Suárez (México, Jus, 1948).

GonZÁlez Obregón, Luis (compilador), Fray Melchor de Talamantes, Biografía y escritos póstumos (México, Secretaría de Relaciones Exteriores, 1909 reeditada como Fray 
Melchor de Talamantes, Argumentos a favor de la Independencia de México ("Presentación” y bibliografía de Luis González y textos, México, Ediciones del Centro de Documentación Política, 1979).

GonZÁlez, María del Refugio, El Derecho indiano y el derecho provincial novohispano. Marco historiográfico y conceptual (México, Universidad Nacional Autónoma de México, 1995).

Icaza Dufour, Francisco de, "Plus Ultra". La Monarquía Católica en Indias, 14921898 (México, Porrúa - Escuela Libre de Derecho, 2008).

Im Hof, Ulrico, La Europa de la ilustración (traducción de Bettina Blanc, Barcelona, Crítica, 1993).

Medina, José Toribio, Historia del Tribunal del Santo Oficio de la Inquisición en Chile (Santiago de Chile, Fondo Histórico y Bibliográfico, 1952).

Medina, José Toribio, Historia del Tribunal del Santo Oficio de la Inquisición en México (2a edición ampliada por Julio Jiménez Rueda, México, Ediciones Fuente Cultural, 1952).

Miquel i Vergés, José María, Diccionario de Insurgentes (2a edición, México, Porrúa, 1980), s. v. "Fray Melchor de Talamantes".

Miranda, José, El influjo politico de Rousseau en la Independencia mexicana, en Presencia de Rousseau. A los 250 años de su nacimiento y a los dos siglos de la aparición del Emilio y El contrato social (México, Universidad Nacional Autónoma de México, 1962).

Miranda, José, Vida colonial y albores de la Independencia (México, Secretaría de Educación Pública, 1972).

Muro Orejón, Antonio, Lecciones de historia del derecho hispano-indiano (México, Porrúa - Escuela Libre de Derecho, 1989).

Ots Capdequí, J. M., El Estado español en Indias (México, Fondo de Cultura Económica, 1993).

Pampillo Baliño, Juan Pablo, El primer constitucionalista de México. Talamantes: ideología y proyecto para la América Septentrional (México, Porrúa, 2010).

Pampillo Baliño, Juan Pablo, Historia general del derecho (México, Oxford, 2008).

Pampillo Baliño, Juan Pablo, Historia general del derecho (México, Oxford, 2008).

Pérez Cayana, María Luisa, Christian Wolff (Madrid, Ediciones del Orto, 1995).

Pérez-Marchand, Monelisa Lina, Dos etapas ideológicas del siglo XVIII en México a través de los papeles de la Inquisición (México, Colegio de México, 1945).

Rodríguez Paniagua, José María, Historia del pensamiento jurídico (Madrid, Universidad Complutense, 1996).

Romero del Valle, Emilia, Fray Melchor de Talamantes, en Historia Mexicana. Revista trimestral publicada por El Colegio de México, 11 (México, 1961).

Rommen, Heinrich, La teoría del estado y de la comunidad internacional en Francisco Suárez (traducción por Valentín García Yebra, Buenos Aires - Madrid, Instituto de Derecho Internacional de Buenos Aires - Instituto Francisco de Vitoria de Madrid, 1951).

Rubio, José. ¿Democracia o representación? Poder y legitimidad en Rousseau (Madrid, Centro de Estudios Constitucionales, 1990).

Soberanes Fernández, José Luis, Historia del derecho mexicano (10ª edición, México, Porrúa, 2003).

Stoetzer, Carlos, Las raices escolásticas de la emancipación de la América Española (Madrid, Centro de Estudios Constitucionales, 1982).

StOetzer, Carlos. El pensamiento político en la América Española durante el periodo de 
la emancipación (1789-1825). Las bases hispánicas y las corrientes europeas (Madrid. Instituto de Estudios Políticos, 1966).

Tau AnzoÁtegui, Víctor, ¿Qué fue el derecho indiano? (Buenos Aires, Abeledo Perrot, 1982).

Tomás y Valiente, Francisco, Manual de historia del derecho español (4a edición, Madrid, Tecnos, 1997).

Torre Rangel, Jesús Antonio de la, Lecciones de historia del derecho mexicano (México, Porrúa, 2005).

Torre Villar, Ernesto de la, La independencia de México (México, Fondo de Cultura Económica, 1992).

Torre Villar, Ernesto de la, La Constitución de Apatzingán y los creadores del Estado mexicano (México, Universidad Nacional Autónoma de México, 1978).

VAllet de Goytisolo, Juan, Montesquieu: Leyes, gobiernos y poderes (Madrid, Civitas, 1986).

VillaVerde, María José, Rousseau y el pensamiento de las luces (Madrid, Tecnos, 1987). VILley, Michel, Los fundadores de la escuela moderna del derecho natural (Buenos Aires, 1978).

VILloro, Luis. El proceso ideológico de la Revolución de Independencia (México, Universidad Nacional Autónoma de México, 1983). 